\title{
Extensão universitária: uma perspectiva de acadêmicos da área da saúde
}

\author{
University extension: a perspective of health academics
}

\author{
Karine Braz Souza Caixeta ${ }^{1}$, Wellyson da Cunha Araújo Firmo²
}

\begin{abstract}
Resumo: Universidade é sustentada por ensino, pesquisa e extensão. Estas funções devem ser equivalentes e ter total importância nas instituições de ensino superior. O objetivo deste trabalho é verificar o conhecimento e a perspectiva de graduandos da área da saúde de uma faculdade particular do Maranhão sobre a prática de extensão universitária. Foram coletadas informações de 100 estudantes da área da Saúde durante o mês de dezembro de 2015. Os alunos responderam questões objetivas sobre a prática de extensão universitária já realizada no âmbito da faculdade. Mais da metade dos entrevistados afirmaram já ter realizado algum trabalho de extensão universitária na instituição. No entanto, grande parte realizou o trabalho de extensão em poucas disciplinas. Isso vem alertar sobre a importância do incentivo desse tipo de atividade por parte dos docentes e por toda a direção acadêmica. O estudo realizado nesta faculdade particular mostra que ainda há uma longa trajetória a ser percorrida pelas universidades em relação à extensão universitária.
\end{abstract}

Palavras-chave: Extensão universitária, saúde, Maranhão.

\begin{abstract}
The University is supported by teaching, research and extension. These functions shall be equivalent and have full importance in higher education institutions. The aim of this study is to verify the knowledge and graduate students from the perspective of the health of a particular college of Maranhão on the practice of university extension. information of 100 students from the health area were collected during the month of December 2015. The students answered objective questions about the university extension of practice already carried out within the college. More than half of respondents said they had done some university extension work at the institution. However, much conducted the extension work in a few disciplines. This comes warn of the importance of encouraging this type of activity on the part of teachers and throughout the academic direction. The study in this particular college shows that there is still a long path to be traveled by the universities regarding the university extension.
\end{abstract}

Keywords: Continuing education, health, Maranhão.

1 - Bacharel em Biomedicina - Pós-graduando em Docência do Ensino Superior pela Faculdade de Educação de Bacabal - FEBAC.

2 - Docente - Curso de Pós-Graduação Faculdade de Educação de Bacabal - FEBAC. 


\section{Introdução}

A Universidade é sustentada por três pilares: ensino, pesquisa e extensão. Estas funções básicas devem ser equivalentes e ter total importância nas instituições de ensino superior. O artigo 207 da Constituição Brasileira dispõe que, as universidades gozam de autonomia didático-científica, administrativa e de gestão financeira e patrimonial e obedecerão ao princípio da dissociabilidade entre ensino, pesquisa e extensão ${ }^{1}$.

A Extensão Universitária é o processo educativo, cultural e científico que articula o Ensino e a Pesquisa de forma indissociável e viabiliza a relação transformadora entre Universidade e Sociedade. A Extensão é uma via de mão-dupla, com trânsito assegurado à comunidade acadêmica, que encontrará, na sociedade, a oportunidade de elaboração da prática de um conhecimento acadêmico. No retorno à Universidade, docentes e discentes trarão um aprendizado que, submetido à reflexão teórica, será acrescido àquele conhecimento ${ }^{2}$.

Segundo Orço, identificamos na Extensão, pelo menos três funções: a função acadêmica, que fundamenta as bases teórico metodológicas; a função é social, pois promove a organização social e a construção da cidadania e por fim identificamos uma função articuladora, do saber e do fazer e da universidade com a sociedade ${ }^{3}$.

A extensão é como uma situação educativa, em que educadores e educandos assumem 0 papel de sujeitos com capacidade de conhecer, mediatizados pelo objeto que desejam conhecer. É uma necessidade no processo de aprendizagem, já que sem esta se corre o risco de trabalhar com uma interpretação ingênua e deturpada da realidade ${ }^{4}$.

Castro afirma: "no caso da extensão, o que percebemos é que ela produz conhecimento a partir da experiência e, assim, tem capacidade de narrar sobre o seu fazer". Assim, o graduando necessita da prática de extensão para um completo aprendizado. É através da extensão que este aluno terá a oportunidade de conhecer a realidade fora da sala de aula, de ter acesso à comunidade e de transmitir valores já discutidos na faculdade ${ }^{5}$.

Os cursos da área da saúde precisam oferecer além do conhecimento teórico. É necessário que - aluno adquira experiências em estágios e trabalhos de extensão. As Diretrizes Curriculares Nacionais para os Cursos de Graduação buscam promover um perfil generalista, humanístico, crítico e reflexivo nas Ciências Biológicas ${ }^{6}$.

Os trabalhos de extensão poderão ser realizados em hospitais, escolas, farmácias, creches, unidades básicas de saúde, abrigos de idosos e até em ambientes abertos como avenidas e rodoviárias. Para que isso aconteça de forma organizada, é importante que haja um planejamento entre docentes e coordenadores da instituição de ensino. Objetivos deverão ser traçados de acordo como o investimento financeiro a ser oferecido pela instituição de ensino. Devem ser realizados os devidos orçamentos e custeios e a melhor data de realização da extensão, de acordo com 0 calendário acadêmico. A instituição de ensino deve dispor de ofícios e documentos de autorizações para serem levadas aos responsáveis pelo estabelecimento da prática de extensão. Tudo isso deverá ser documentado através de um pré-projeto 
escrito. Após o trabalho realizado, deverá também ser publicado e documentado na própria instituição, como parte de suas atribuições.

O objetivo deste trabalho é verificar o conhecimento e a perspectiva de graduandos da área da saúde de uma faculdade particular sobre a extensão universitária e sua importância na formação acadêmica.

\section{Material e Métodos}

Trata-se de um estudo analítico com corte transversal e abordagem quali-quantitativa, realizada em uma faculdade particular do Município de Bacabal-MA. A cidade fica localizada a 240 km da capital São Luís.

Foram coletadas informações de 100 estudantes da área da Saúde, alunos dos cursos de Farmácia, Enfermagem e Nutrição durante o mês de dezembro de 2015. Os acadêmicos responderam um questionário baseado em um conjunto de questões objetivas e de múltipla escolha, levando-se em consideração 0 conhecimento e a prática de extensão universitária já realizada no âmbito da faculdade. O número amostral foi escolhido por conveniência.

Os discentes que aceitaram participar da pesquisa assinaram um Termo de Consentimento Livre e Esclarecido.

O presente estudo seguiu os preceitos preconizados pela Resolução no 466/12, que versa sobre pesquisa com seres humanos. Os dados foram organizados em gráficos e tabelas utilizando os programas Microsoft Office Word e Excel.

\section{Resultados e Discussão}

A dinâmica extensionista institucional envolve formatos ou modalidades que se diferenciam, principalmente, quanto à finalidade, como define o Fórum de Pró-Reitores das Universidades Públicas Brasileiras $(2000)^{7}$. Estas ações podem ser cursos para os graduandos, eventos de interesse acadêmico, projetos em função dos interesses das comunidades e que visam a contribuir para a formação acadêmica do aluno ou serviços oferecidos a comunidade, de caráter permanente ou eventual.

Os acadêmicos eram de três cursos da área da Saúde, sendo 27\% do curso de Nutrição, $64 \%$ do curso de Farmácia e $9 \%$ do curso de Enfermagem. Em relação ao sexo, 81\% eram do sexo feminino e $19 \%$, do sexo masculino. A maior faixa etária foi entre 18 a 23 anos, correspondendo a $79 \%$ dos alunos. A renda familiar prevalente foi de até 2 salários mínimos.

Quando indagados sobre o significado de extensão universitária, $75 \%$ responderam ser uma ação de uma universidade junto à comunidade, disponibilizando ao público externo o conhecimento adquirido em sala de aula. 14\% afirmaram ser uma produção de conhecimento sobre algum assunto dentro da universidade, $2 \%$ um estudo em sala de aula sobre algum assunto e $9 \%$ não souberam responder. Os demais resultados serão apresentados em gráficos. 
Gráfico 1 - Você já realizou algum trabalho de extensão nesta Instituição de Ensino Superior?

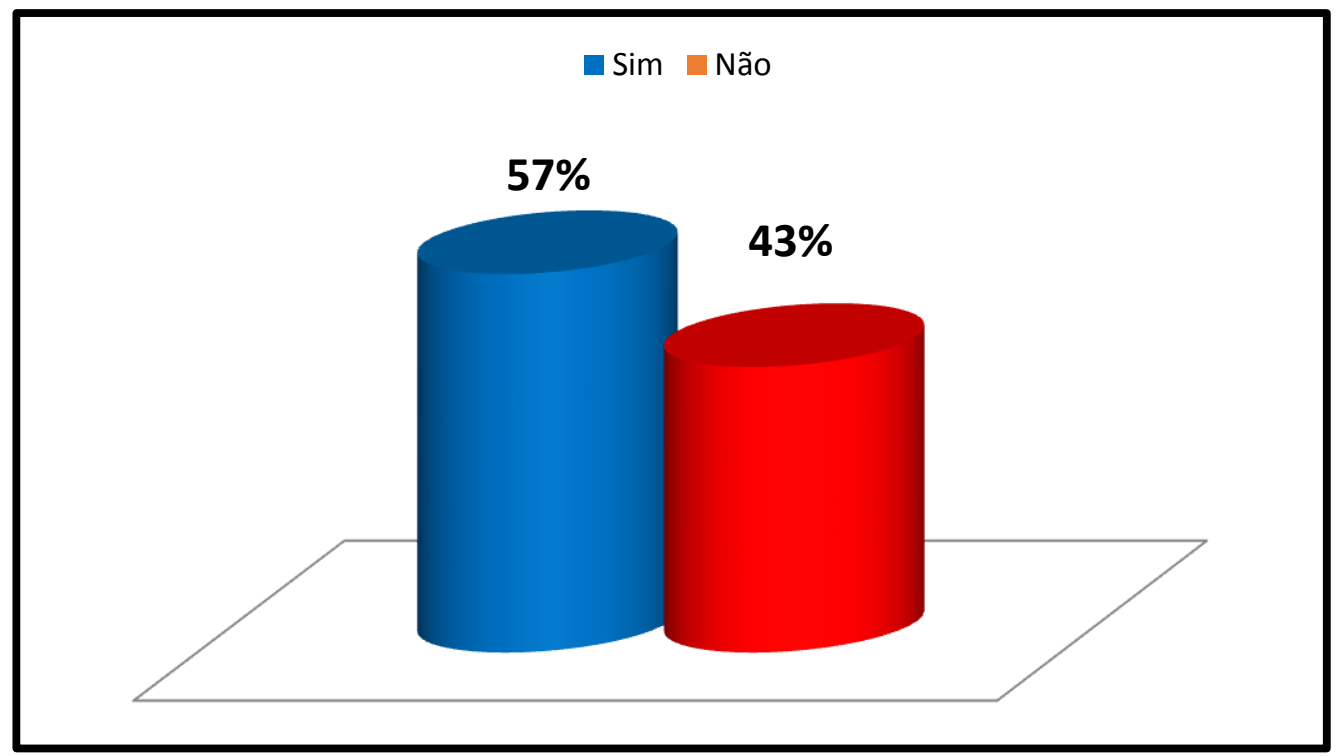

Gráfico 2 - Você foi solicitado a realizar atividades de extensão como estratégia de aprendizagem?

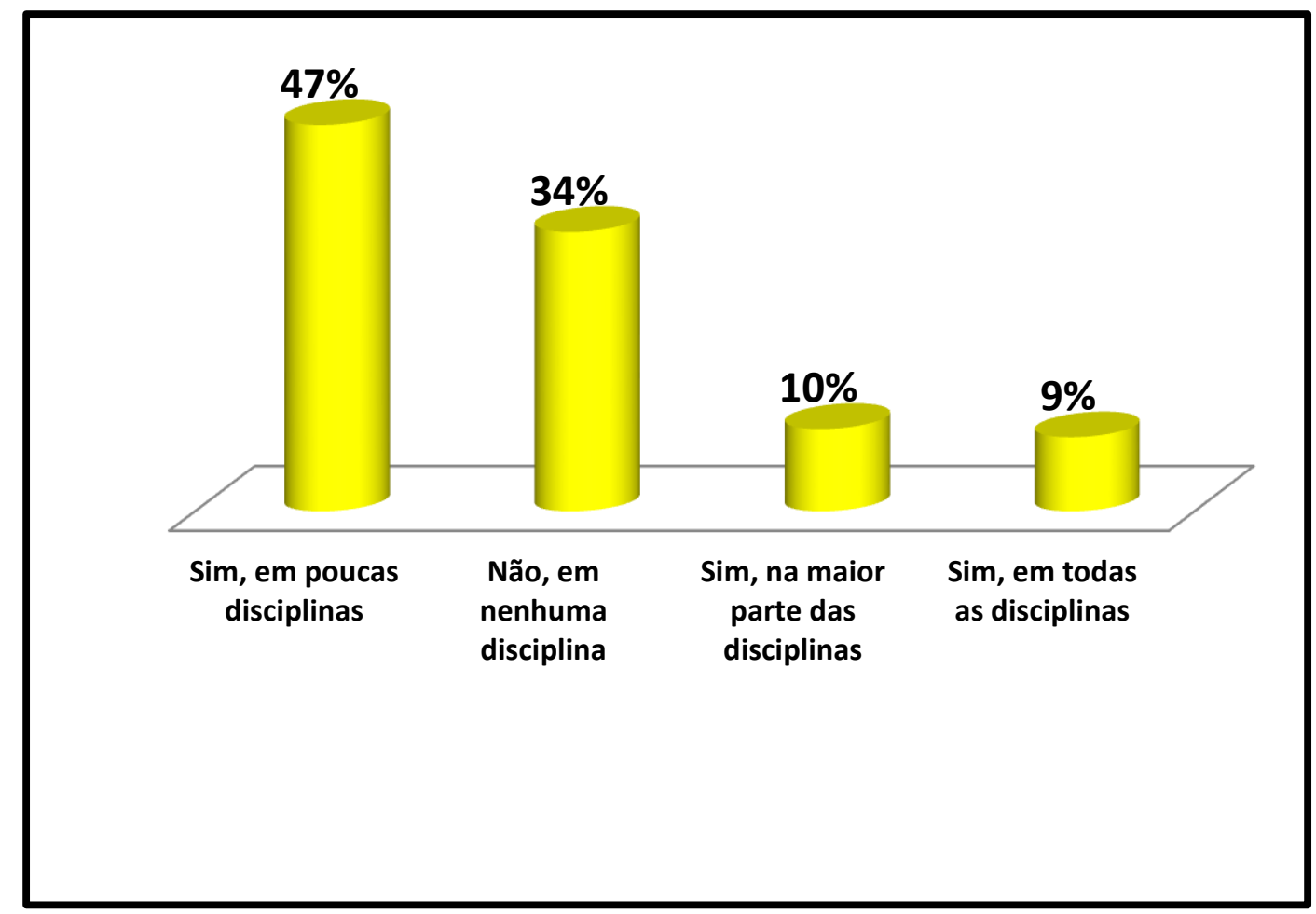


A extensão universitária é uma forma de interação que deve existir entre a universidade e a comunidade na qual ela está inserida, uma espécie de ponte permanente entre a universidade e os diversos setores da sociedade. Funciona como uma via de duas mãos em que a universidade leva conhecimentos e/ou assistência à comunidade e recebe dela influxos positivos em forma de retroalimentação, tais como suas reais necessidades, anseios e aspirações $^{8}$.

Nesta pesquisa, 57\% dos alunos entrevistados disseram já ter realizado algum trabalho de extensão universitária na instituição. No entanto, quase a metade afirmou ter realizado o trabalho de extensão em poucas disciplinas. Isso vem alertar sobre a importância do incentivo desse tipo de atividade por parte dos docentes e por toda a direção acadêmica. Muitos docentes ainda enquadram o ensino superior apenas em atividades no contexto de sala de aula, esquecendo-se de que as atividades práticas fora do ambiente da instituição podem contribuir significativamente para a construção do conhecimento. De fato, a preocupação das universidades deve ser de formar cidadãos para atuarem no mundo. Para tanto, o currículo não pode se limitar a simples transmissão de conhecimentos ${ }^{8}$.

A relevância da educação superior deve ser avaliada em termos da concordância entre o que a sociedade espera da instituição e o que a instituição realmente faz ${ }^{9}$. Sair da sala de aula e ir para uma comunidade é uma forma de o acadêmico interagir com a sociedade em que a faculdade está inserida e buscar as reais necessidades desta comunidade, tendo também a oportunidade de conhecer as expectativas da população em relação a um profissional.

A atividade de extensão deve ser um dos principais componentes para a reflexão quanto ao papel do ensino superior neste novo milênio, pois quando as necessidades forem naturalmente percebidas pela comunidade acadêmica e incluídas no seu fazer, as IES estarão cumprindo com a sua finalidade ${ }^{10}$.

Gráfico 3 - Se já realizou, onde aconteceu o trabalho de extensão?

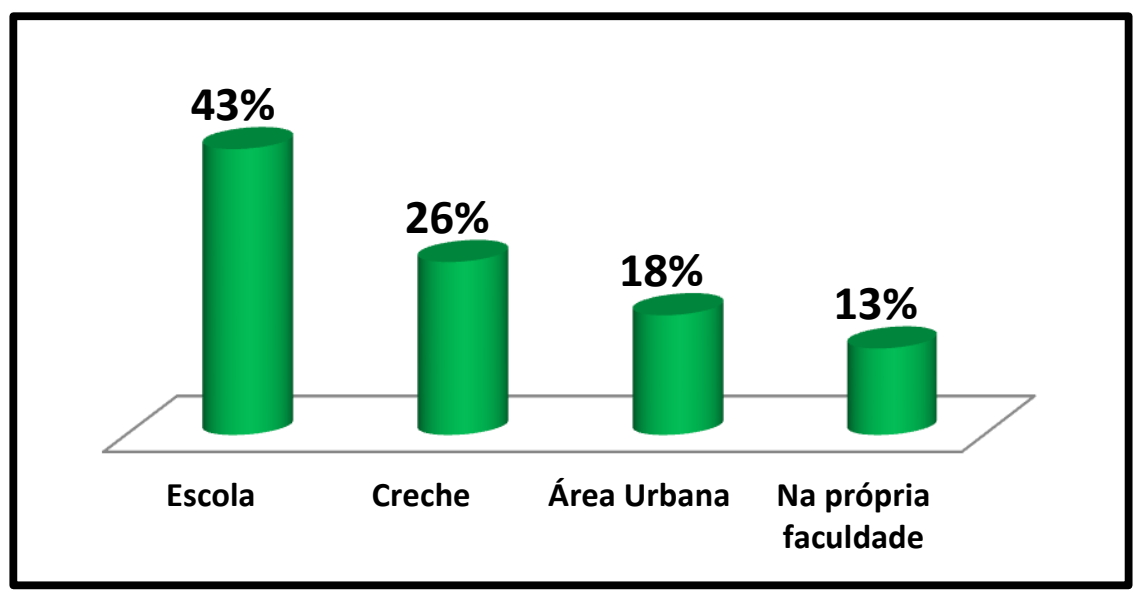


Muitos são os locais propícios para a prática de trabalhos de extensão. Nesta pesquisa, a maior frequência ocorreu em escolas de ensino fundamental e médio. Talvez isso se deva ao fato de que escolas estejam mais abertas a receber os acadêmicos e também disporem de uma estrutura física apropriada, em pátios, ginásios de esportes e salas de aula. No entanto, não existem limites em relação às atividades de extensão. Os alunos podem ter acesso a vários ambientes como laboratórios, indústrias, hospitais, organizações não governamentais, empresas públicas e privadas e até mesmo avenidas e praças. Cabe ao docente transformar esta visita numa forma de educar e de agregar conhecimento aos estudantes.

O ensino rompe as barreiras da sala de aula e sai do ambiente fechado da Universidade, para que haja a troca de informações provenientes do ambiente primordial. Assim, o conteúdo passa a ser multi, inter e transdisciplinar ${ }^{11}$.

Gráfico 4 - A Instituição de Ensino Superior apoia a participação dos estudantes em trabalhos de extensão?

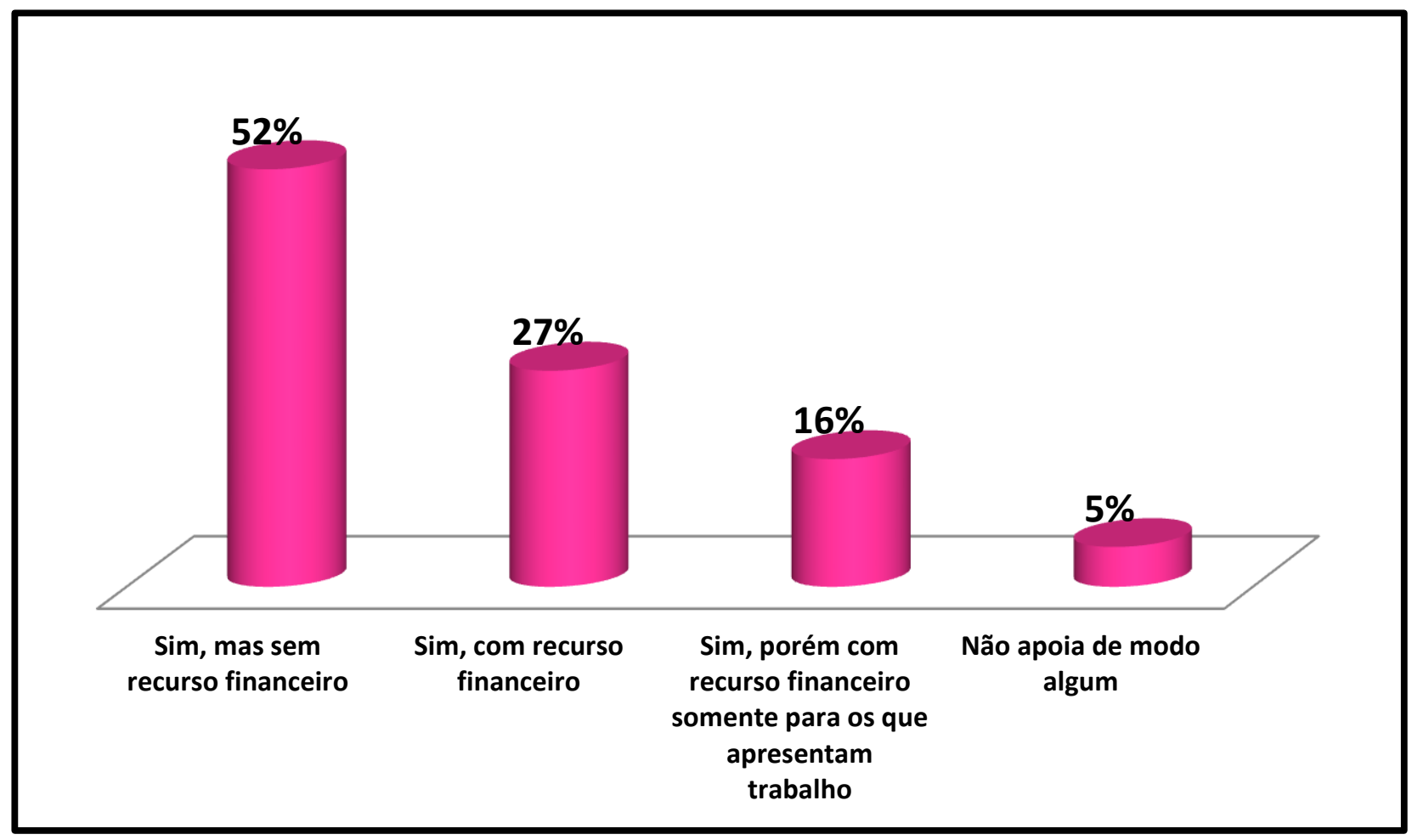


não $\begin{gathered}\text { Observou-se que os projetos } \\ \text { costumam }\end{gathered}$ parcerias para apoio financeiro. Isso acontece provavelmente por falta de conhecimento dos docentes sobre ajuda financeira oferecida por instituições públicas que apoiam as universidades, escassez de editais na própria instituição para a prática de extensão ou até mesmo, falha dos professores, que não planejam com antecedência os trabalhos que serão desenvolvidos no decorrer do semestre.

Segundo Jezine ${ }^{12}$ "a prática de extensão universitária se opõe à ideia de que constitua uma atividade menor na estrutura universitária, a ser realizada por professores sem titulação, nas sobras de tempo disponível, e que o trabalho junto às comunidades carentes é uma solidariedade individual". Para a autora, a extensão não deve ser subestimada ou tida como uma atividade sem importância. Deve ser planejada e executada com disciplina e antecedência para que tenha sucesso e apoio financeiro em sua realização.

Atualmente, existem muitas instituições federais e estaduais que financiam trabalhos de extensão nas universidades. Para participar, é necessário que a instituição se inscreva nos editais semestrais e submeta um projeto de extensão com um prazo de antecedência. Verifica-se aqui a necessidade de que a instituição de ensino estimule os professores a submeter seus projetos em editais da própria faculdade ou de outras instituições.

Calipo $^{13}$ (p.4) diz que "[...] [os] projetos de extensão universitária crítica facilitam uma aprendizagem de saberes recíprocos e devem agregar integrantes da universidade e da comunidade popular, sob uma linha horizontal do conhecimento [...]". Neste contexto, aborda-se que no processo da extensão, existe uma via de mão dupla na aprendizagem. Tanto o acadêmico quanto a comunidade ensinam e aprendem num processo interdisciplinar.

Para Pierson e outros 14 , "a inserção da extensão requer uma flexibilização da estrutura curricular que viabilize o envolvimento dos alunos com atividades de extensão que pudessem ser creditadas como componente curricular." Essas atividades de extensão deverão ser exercidas de forma contínua durante todo o curso superior e na maioria das disciplinas, principalmente nos cursos da área da saúde.

$\begin{aligned} & \text { Segundo } \\ & \text { Vasconcelos }\end{aligned}$, "o $\begin{array}{r}\text { e } \\ \text { papel }\end{array}$
transformador da
universitária somente podensão
firmar como práxis de uma
universidade quando professores,
alunos, pessoal
administrativo técnico-
assumirem o compromisso com a
transformação da realidade
educacional brasileira".

\section{Conclusão}

O estudo realizado nesta faculdade particular mostra que ainda há uma longa trajetória a ser percorrida pelas universidades em relação à extensão universitária. Estas atividades precisam ser estimuladas e valorizadas pela direção acadêmica e planejadas pelos docentes, como todas as outras atividades curriculares. Os alunos precisam ser orientados sobre a importância dos trabalhos de extensão desde o primeiro 
período do curso e terem ciência de que se trata de uma atividade de construção de conhecimento interdisciplinar junto a outras comunidades, sendo uma aprendizagem horizontal.

Cursos, eventos e projetos voltados para os acadêmicos também são práticas de extensão que precisam ser realizadas no ambiente da própria faculdade. Estas ações estimulam a pesquisa e a iniciação científica, comprovando que os pilares ensino, pesquisa e extensão estão totalmente ligados e são indissociáveis.

um ara que a extensão tenha comunidade, são necessários recursos financeiros. Torna-se de suma importância desenvolver estratégias de captação de recursos através de bolsas oferecidas pela própria faculdade ou de programas governamentais e outras parcerias, como por exemplo, empresas e indústrias particulares.

\section{Referências}

1. Brasil. Ministério da Educação e Cultura. Diretrizes Curriculares Nacionais para os Cursos de Graduação em Ciências Biológicas. Brasília, 6 nov. 2001. Disponível em: Acesso em: 4 jun. 2005.

2. BRASIL. Plano Nacional de Extensão Universitária. Disponível em:

http://www.uniube.br/ceac/arquivos/ PNEX.pdf Acesso em: 7 jan. 2009.

3. Orço, Cláudio Luís; Vicentini, Rosiclei Brandalise. Programa de Extensão universitária: uma ação educativa. Revista Saúde em Debate, v. 27, n. 65. 2013.
4. Freire, Paulo. Extensão ou Comunicação? Rio de Janeiro: Paz e Terra, 1983, 93p.

5. Castro, Luciana M. Cerqueira. A Universidade, a extensão universitária e a produção de conhecimentos emancipadores. In: 27aㅡ Reunião Anual da ANPED Sociedade, Democracia e Educação: Qual Universidade? 2004, Caxambu. http://www2.uerj.br/anped11, 2004.

6. BRASIL. Ministério da Educação. Parecer CNE/CES n.213, de 9 de outubro de 2008. Dispõe sobre carga horária mínima e procedimentos relativos à integralização e duração dos cursos de graduação em Biomedicina, Ciências Biológicas, Educação Física, Enfermagem, Farmácia, Fisioterapia, Fonoaudiologia, Nutrição e Terapia Ocupacional, bacharelados, na modalidade presencial. Brasília: Ministério da Educação, 2008. Disponível em: $<$ http://portal.mec.gov.br/dmdocume nts/pces213_08.pdf>. Acesso em: 15 dez. 2008.

7. PLANO NACIONAL DE EXTENSÃO UNIVERSITÁRIA. Fórum de PróReitores de Extensão das Universidades Públicas Brasileiras e SESu/MEC. Edição Atualizada, 2000/2001.

8. Nunes, Ana Lucia de Paula Ferreira; Da Cruz Silva, Maria Batista. A extensão universitária no ensino superior e a sociedade. Revista MalEstar e Sociedade, Minas Gerais, v. 4, n. 7, p. 119-133, 2011.

9. UNESCO - Organização das Nações Unidas para a Educação, a Ciência e a Cultura. Conferência mundial sobre educação superior. v. 14. Paris: UNESCO, 1998.

10. SOARES, V. L. A. O papel social das IES: contribuição do ensino superior particular. Revista do Centro de Estudos Sociais 
Aplicados, Belém, n. 6, p. 8, out. 2003.

11. Rodrigues, Andréia Lílian Lima. et al. Contribuições da extensão universitária na sociedade. Cadernos de Graduação - Ciências Humanas e Sociais, Aracaju, v. 1, n.16 | p. 141-148, mar. 2013

12. Jezine, Edineide. As Práticas Curriculares e a Extensão Universitária. In: CONGRESSO BRASILEIRO DE EXTENSÃO UNIVERSITÁRIA, 2. Anais do. Belo Horizonte. Acesso em: 15 mai. 2005.

13. Calipo, Daniel. Projetos de extensão universitária crítica: Uma ação educativa transformadora. Campinas, 2009. Base de dados do Scielo.

14. Pierson, Alice Helena Campos; Cortegoso, Ana Lucia; Araújo Filho, Targino de. Flexibilização curricular: experiências e perspectivas. In: Thiollent, Michel; Castelo Branco, Alba Lúcia; Guimarães, Regina Guedes Moreira; Araújo Filho, Targino de. (org.). Extensão universitária: conceitos, métodos $\mathrm{e}$ práticas. Rio de Janeiro, v. 1, p. 4155, 2003.

15. Silva, Maria do Socorro; Vasconcelos, Simão Dias. Extensão Universitária e Formação Profissional: avaliação da experiência das Ciências Biológicas na Universidade Federal de Pernambuco. Estudos em Avaliação Educacional, v. 17, n. 33, jan./abr. 2006. 